\title{
CONCEPTUAL SPECIFICATIONS REGARDING THE PRIMACY OF SYSTEM AUDITING OVER OTHER TYPES OF AUDITING WITHIN THE MINISTRY OF DEFENSE
}

\author{
Sebastian FLOŞTOIU \\ Teritorial Internal Audit Section no. 5, Brașov, Romania \\ sebitic@yahoo.com \\ Marius MILANDRU \\ “Nicolae Bălcescu” Land Forces Academy, Sibiu, Romania \\ mnmilandru@yahoo.com
}

\begin{abstract}
At present, continuous effort is being made, in the field of internal public auditing, at the level of the Internal Auditing Board, to shift from compliance auditing, that verifies the accordance of the performed activities to the law, to system auditing which aims to monitor both the aspect of compliance and that of assessing the achievement of objectives within the frame of economy, efficiency and effectiveness. Consequently, we can state that system auditing is a result of the two types of auditing (compliance and operational) and that its promotion is of utmost necessity, due its superior quality. Within this general context, this study approaches system auditing in a logical manner, presenting a positive attitude and vision by setting forth opinions regarding the role of system auditing within missions of protection. Our purpose is to identify ways and solutions towards improving internal public system auditing within the MoD.
\end{abstract}

KEYWORDS: system auditing, objectives, results, internal managerial control system

\section{Introduction}

Since 1999, Romania has been engaged in an extensive reforming process of the Internal Public Financial Control System. This endeavor started, as it was logical, with the drafting, together with European Union experts, of a strategic document - Policy Paper - completed in October 2001, which established the framework of the future internal auditing system in the public sector.
Thus, auditing was being implemented in our country as a necessity to correlate internal norms with that of the European legislation. In this context, internal auditing was defined by the G.O. no. 119/1999 as "an independently organized activity within the structure of a public institution and under the direct supervision of its leader, which aims to verify, inspect and analyze its own system of internal control in view of an objective evaluation of the extent to which the public 
institution fulfills its objectives and uses its own resources economically, efficiently and effectively and, to report to administration the findings, the identified weaknesses, and the proposed measures of correction of deficiencies and enhancement of operation".

It is fair to say the G.O. no. 119/1999 has represented the "birth certificate" of internal public auditing, as the basic official definition of this activity in our country, which established, for the first time, responsibilities and qualifications of the auditing entities. Nevertheless, since it didn't specify separately the attributions for internal control and, especially, inventory control, it has generated a lot of confusion that still persists.

The normative framework for the activity of internal public auditing was completed in 2002 when the Law no. 762 regarding internal public auditing and the Norms regarding the organization and practice of the activity of internal public auditing were adopted. The initial law has been changed repeatedly, due to the economic and social circumstances of our society as well as the good practices and the experience accumulated by the auditing bodies in the nearly ten years of activity. The normative framework was updated by the Law no. 191/2011 regarding the modification and completion of Law no. 762/2002 regarding internal public auditing. Consequently, since the law for auditing was modified, it was necessary to adopt new norms in the practice of internal public auditing in G.O. no. 1086/2013.

At present, we can state that we have an adequate and coherent institutional frame for the highest-quality practice of internal public auditing in all public institutions.

\section{The Superiority of System} Auditing as Compared to Other Types of Auditing

According to INTOSAI classifications, standards 39 and 40, as well as national regulations - art. 14 of Law no. 672/2002 republished, three types of internal public auditing are mentioned:

- compliance auditing examines the action over financial effects in public funds or public patrimonies, from the point of view of compliance to principles, regulations, and methodological aspects that are applicable to them;

- operational auditing examines if the criteria established for the implementation of objectives and tasks assigned to the public entity are correct for the evaluation of results and assesses if the results are correlated with the objectives;

- system auditing represents a thorough analysis of the administrative and control systems with the aim of establishing if they operate in an economic, efficient and effective way and of identifying deficiencies and correcting them.

For a better understanding of the defining elements for each auditing category, and to emphasize the superiority of system auditing over other types within missions of protection we are presenting elements that represent similarities and differences among them.

Furthermore, as a result of the analysis of the table above, and of our findings throughout the course of our experience as internal auditors, we can state the following:

a. Compliance auditing represents the most widespread type of auditing mission, providing the basis for the other types (operational and system). In the case of a compliance mission, the auditor verifies the compliance with the norms applicable in the audited area (laws, order, rules, internal norms, etc.).

Compliance auditing monitors the following: compliance with the laws and norms (internal and external), the observance of rules in transactions and the protection of the patrimony. Its characteristics are the following: 
- YES/NO conclusion: rules are obeyed/not obeyed;

- the activity is easy;

- does not require a high level of knowledge;

- past-oriented (compliance with the rules is analyzed in a past period);

- requires a great amount of resources (a great number of transactions and operations is analyzed);

- monotonous;

- it can lead to the rejection of the auditing action by the audited entity, through the claim of 'chasing mistakes'.

In conclusion, compliance auditing is a limited approach to auditing, even though it represented a very useful tool in the beginning of internal auditing, when a context of marked legislative instability lead to human errors due to lack of knowledge in normative specifications, and their misinterpretation and mistaken employment. Nevertheless, it is not recommended to abandon the practice of this type of auditing, as the present tendency is to make it a part of system or operational auditing.

b. Operational auditing is preferred by public auditors, since this type of missions assure the increase of management responsibility for their decisions and actions. As a difference from compliance auditing, which verifies the observance of the applicable norms, operational auditing relies very much on reasoning.

This type of auditing investigates if the markers are adequate for monitoring the performance (activities) of the entity, if the results correspond with the objectives and if the impact obtained is the one intended. It can be assimilated with a management auditing or one that analyses the 'three Es' (economy, efficiency, effectiveness).

Operational auditing pursues the following aspects:

- economy and efficiency;

- reaching objectives (effectiveness);

- validity of information.
Consequently, it can be stated that operational auditing is a more sophisticated process, yet, it doesn't convey an overall image of the evaluated system, since it focuses exclusively on the economy, efficiency and effectiveness of actions.

c. System auditing sets off from the fact that the audited entity operates as a system that includes several interconnected subsystems (e.g. salaries, logistics, etc.). Hence, the input (resources) passes through certain processes through which the output (result) is obtained. Also, this type of auditing relies on the results of systems that represent inputs for other systems. The way of operation and the performances of a system can affect the operation and performance of other component systems.

Envisioning the entity as a network of other systems represents a horizontal approach of system auditing. Nevertheless, system auditing within an organization can be completed through an analysis of the components by approaching the same systems and processes in several entities within the organization. The auditing of the maintenance system within the MoD can provide an example.

System auditing pursues especially the following aspects:

- compliance with laws and norms (internal and external);

- observance of rules in transactions;

- protection of the patrimony;

- economy and efficiency;

- reaching objectives;

- validity of information.

As it is revealed, system auditing includes both the compliance and the operational component for the evaluated system. Also, as a difference from compliance auditing, that assures protection to audited entities, and important characteristic of system auditing is counseling.

The main characteristics of system auditing are: 
- system auditing starts with the thorough analysis of what a system consists of: input, processes, output;

- the auditing activity focuses on the assessment of the control within the subsystems of the organization to verify if their specific objectives are completed so that the main objectives of the system are completed as well.

Analyzing the characteristics of the system auditing, the main advantages of this type of auditing are the following:

- system auditing provides a higher degree of protection to the audited entity with the same consumption of resources as the auditor concentrates on the in-depth analysis of the control apparatus and assesses the compliance of operations merely indirectly; if these investigations are adequate, the system objectives can be fulfilled at present and in the future;

- it approaches the system in its entirety, allowing the provision of an image on the operation of the whole system, of its performance, and the degree to which it reaches its goals;

- a higher degree of openness from the audited entities/bodies to identify solutions regarding the operation of the evaluated subsystem/system.

As for disadvantages of this type of auditing, we can mention:

- system auditing requires of the auditor a high degree of professional qualification; auditors must understand system-based auditing, and this type of training can consume many resources;

- the auditor examines fewer transactions, which means fewer operations of examination and certification; the focus lies mainly on monitoring control devices and less on identifying anomalies or on risk management.

In view of a relevant and quality evaluation, as well as a recommendation that leads to the enhancement of the processes within the system, our opinion is that this type of auditing must seek to find answers to the following questions:

- Which is the normative framework that regulates and governs activities within the evaluated system, and is it adequate? Which are the general and specific objectives of the audited system?

- Which objectives of the evaluated system are SMART (S-specific, M-measurable, A-appropriate, R-realistic, T-time-dependent)?

- Which is the configuration of the system as reported to the achievement of the desired objective?

- Has an internal managerial control system been implemented at the level of the analyzed system and does its structure ensure the conditions to manage the risks of failure in objective accomplishment?

- Which is the degree of compliance of the processes undertaken within the system during the analysis?

- Have performance measuring indicators been established within the evaluated system and what was the level of accomplishment?

- Which are the solutions and recommendations that can lead to a better operation of the system?

\section{Distinctive Features of Internal Public System Auditing Missions within the MoD}

In view of the best completion of system auditing mission objectives as well as for a unitary approach of their evolution within the MoD the Methodological Norms Regarding the Practice of Internal Public Auditing in the MoD have been drafted and approved.

The Order of the Ministry of National Defense no. M 67/2014 has been approved as a set of specifications regarding the way of organizing and completing system auditing missions.

In view of obtaining relevant conclusions about the operation of systems identified within the MoD (maintenance, 
education, research, medical, etc.) system auditing missions are organized by the Internal Auditing Board for the whole ministry, with auditing teams for each territorial department, that complete the auditing mission in a representative sample of entities within their area of responsibility.

As mentioned before, the organization, coordination and evolution of the system auditing missions obey the methodology of protection missions with the following distinctive features:

- a coordination team is established at Auditing Board level, In view of coordinating the activity of the auditing teams within one area, of integrating and processing the collected data and formulating relevant conclusions in order to release some recommendations towards the decisive factors within the MoD, which may lead to the improvement of operation of the evaluated system.

- for a good development of the system auditing mission the head of the coordination team can decide the organization of meetings among internal auditors appointed to participate to the mission;

- the Internal Auditing Board sends a notification on the execution of the system auditing mission to the coordinating body/head of department of the audited system; at the same time, every audited entity /body is informed by the Board, or, specifically, by the territorial internal system auditing body it is assigned to;

- the collection and processing of the information can be completed by each body/entity that is part of the system or is directly/indirectly connected to it; territorial departments centralize the data and send it to the coordinating team;

- the risk analysis and the schedule of the auditing mission is established by each section and is sent to the coordination team in order to be centralized and drafted into a general schedule of the system auditing mission;
- each internal auditing team intervenes locally, independently and elaborates the documents stipulated by the protection mission methodology;

- the documents for problem identification and analysis are reported to the audited body/entity by the auditing team;

- at the level of each local structure an intermediate internal public auditing report project is drafted based on the findings, conclusions and recommendations formulated by the internal auditors within the audited body/entity.

- the intermediate internal public auditing reports are sent to the coordinating team within the established deadlines in order to draft the centralized report;

- all recommendations formulated in the reports drafted by the subordinated local organizations and transferred to the central report of the system auditing mission, are included into the recommendation followup documents, drafted individually, for each military unit the recommendation is addressed to;

- the central report is sent to the coordinating structures and the audited system and/or the main organizations related to this and extracts of the auditing report are sent to the audited bodies;

$$
\text { - the implementation }
$$
recommendation monitoring is completed by the auditing body that the audited bodies/entities are assigned to; they send periodical reports on the state of implementations to the Board, in order to be recorded and processed.

\section{Suggestions and Personal Views on Completing Missions of Internal Public System Auditing}

Based on the 12 years of experience within auditing bodies in the MoD, as well as the "lessons learnt" due to participation in many system auditing missions we suggest a series of proposals that, in our opinion can lead to an improvement in system auditing missions: 
- we think that a very important role in the success of system auditing missions is played by the preliminary preparation of the mission, so that when the auditing mission is initiated, at the level of coordination and local section teams, depending on the mission objectives from the auditing plan, auditable objectives/activities should be established in a preliminary form by formulating a series of premises/hypotheses, and, possibly, some expected results;

- also, in view of the system auditing mission accomplishment at the highest level, it is essential that among the auditors and the auditing teams the leaders of the audited departments be selected due to their thorough knowledge of the activities that are to be evaluated;

- it would be advisable that all the auditing teams operating on the site during the intervention, use the same type of questionnaires/check-lists, drafted/edited by the coordination team after centralizing the suggestions of the local section;

- in view of gathering relevant data and information for the whole evaluated system and to minimize auditing risk and the occurrence of undetected items, generated by the auditors' competence, real-time dissemination of the clues revealing possible dysfunctions would be beneficial in order to enable inspections in all evaluated bodies/entities;

- for mission success it is beneficial to organize sessions of analysis between the coordinating team and all the heads of the local sections before the start of the mission and the second half of its development, in order to monitor and balance the activities undertaken in the whole evaluated system;

- also, for more relevant results of the auditing, it is important that the selection of the evaluated bodies/entities be made as a result of a thorough risk analysis.

\section{Conclusions}

In the context of the increasing complexity of tasks for public entities, of the continuous development and modification of the legislative framework, of the administrative and financial decentralization, it is necessary for internal auditing to intervene through systematic examination and evaluation of the management processes and the risks taken by the leading staff, as well as draft recommendations for improvement.

Most MoD entities perform predominantly routine compliance internal auditing which, in our opinion, are less conclusive in establishing the level of objective achievement in the entity. System auditing has a smaller proportion in the types of auditing completed as protection missions, even if it could contribute decisively to the efficient operation of the audited entities.

Sustained effort is necessary in order to achieve the transition from auditing which focuses on verifying the observance of rules in transactions, on compliance with the laws, on protection of assets, to system auditing through the addition of relevant analysis regarding objective achievement in terms of economy, efficiency and effectiveness.

In conclusion, we consider that this dimension of internal public auditing will constitute the final phase in the development of this activity within the MoD. 


\section{REFERENCES}

*** International Auditing Standards - 2005, available at: www.cafr.ro.

*** Law no. 672/2002 regarding internal public auditing, republished, with subsequent modifications.

***Law no. 191/2011 regarding the modification and completion of Law no. 762/2002 regarding internal public auditing.

*** Report on the Comparison of compliance, operational and system auditing. drafted through the PHARE RO project 2002/000.586.03.04.13.

*** Resolution of the Romanian Government no. 1086/2013: General norms regarding the practice of auditing activity.

*** The Order of the Ministry of the National Defense no. M 67/2014: Methodological norms regarding the practice of internal public auditing in the MoD. 